\title{
Imaging of plankton specimens with the lightframe on-sight keyspecies investigation (LOKI) system
}

\author{
Jan Schulz \\ jan.schulz@imare.de \\ Kristina Barz \\ kristina.barz@awi.de \\ Patricia Ayon \\ payon@imarpe.gob.pe

\section{Andree Lüdtke} \\ aluedtke@tzi.de \\ Oliver Zielinski \\ oliver.zielinski@imare.de

\section{Dirk Mengedoht \\ dirk.mengedoht@awi.de}

\section{Hans-Jürgen Hirche \\ hans-juergen.hirche@awi.de}

\author{
Institute for Marine Resources, Bremerhaven and University of Applied Sciences, Bremerhaven, \\ Germany \\ Alfred Wegener Institute for Polar and Marine Research, Bremerhaven, Germany \\ Instituto del Mar del Peru, Callao, Peru
}

Centre for Computing Technologies - Image Processing, University of Bremen, Germany

Institute for Marine Resources, Bremerhaven and University of Applied Sciences, Bremerhaven, Germany

Alfred Wegener Institute for Polar and Marine Research, Bremerhaven, Germany

Zooplankton is a key element in aquatic food webs. Rapid mapping of abundance, combined with information on taxonomic and size composition is necessary to understand ecosystem dynamics. Classical sampling with towed plankton nets does not allow resolving fine scale distributions along hydrographic gradients (e.g. fronts and clines) although such structures determine community assemblages and trophic interactions. Furthermore, sample analysis is labor intensive and time consuming. To overcome these shortcomings, Lightframe On-sight Keyspecies Investigation (LOKI), a new imaging device, was developed for sensing spatial variability of plankton distribution on scales below the $1 \mathrm{~m}$ level. Here, we give a brief description of the LOKI system and demonstrate its potential for taxonomic identification using images of various zooplankton taxa collected in the south east Pacific. [D0I: 10.2971/je0s.2010.10017s]

Keywords: zooplankton, imaging, image analysis, lightframe on-sight keyspecies investigation (LOKI), small scale distribution

\section{INTRODUCTION}

Zooplankton community assemblages are often controlled by water mass properties like salinity, temperature or and oxygen content and hydrographical processes on various scales that impact the horizontal and vertical structure of the water column. Depending on physiological requirements and environmental conditions, zooplankton communities can be spatially constrained to water volumes with discriminable environmental conditions. Such structures have a crucial impact on productivity and trophodynamic relationships. Favourable conditions can foster certain species and help to outgrow others, while specimens that cannot escape unfavourable conditions face stress and increased mortality. Therefore understanding interactions among hydrography and zooplankton appearance is a prerequisite to understand ecosystem functioning.

Systematic zooplankton sampling has been carried out since the $19^{\text {th }}$ century. Traditional sampling gears are towed nets to determine horizontal and vertical distribution and abundance. The method-borne integration effect of net sampling makes it difficult to resolve plankton distribution on the scale of hydrographic gradients such as fronts and clines, although such structures strongly impact plankton community assem- blages [1]. Since the 1950s, optical systems have been developed to overcome these limitations (see reviews in [2]-[4]). Nowadays, digital techniques allow in-situ imaging of objects dispersed in water, while sensors concurrently record ambient hydrographic parameters.

Imaging of zooplankton with camera systems faces several problems; (1) image quality must be sufficient for taxonomic identification. Therefore, distances between camera and object have to be short to reduce object blurring at high particle densities and reduced water clarity (e.g. see [5]). The size range of mesozooplankton $(0.1 \mathrm{~mm}$ to $10 \mathrm{~mm})$ requires high magnification to recognise taxonomic features. However, an approximately 1:1 magnification and a large depth of field (DOF) are close to the feasible border of photography due to the laws of optics. High magnification at short distances results in a small DOF and thus in a high proportion of outof-focus objects [6]. DOF is the range within which circles of confusion $(\mathrm{CoC})$ remain small enough that a point in the object plane appears to the human eye as a single point [7]. In digital imaging, it is desirable to keep the diameter of the CoC small to reduce the number of pixels excited simultaneously by the same point. Only points in the object plane are cor- 
rectly imaged as points on a photosensitive sensor in the image plane. With greater distance from the object plane the $\mathrm{CoC}$ get larger. Thus, taxonomic features like fine bristles can only be resolved within a narrow DOF. High f-values (i.e. small aperture opening) enlarge DOF by minimising the $\mathrm{CoC}$, but reduce the light available for exposure. (2) As increased magnification results in a higher relative translational displacement of the drifting fluid and its entrained particles during exposure, very short shutter times are required to avoid motion blurring [8]. On the other hand, shorter exposure times require illumination units of higher power. (3) To assess plankton concentration, an important parameter in plankton ecology, precise knowledge of the volume imaged is necessary. One way to estimate the image volume is the application of software based methods which determine the sharpness of imaged particles (e.g. see [9]). This approach is especially sensitive to calibration in small volumes. Other systems profile plankton and marine snow in much larger volumes (e.g. see [10]-[13]), which makes them less susceptible to unfocussed illumination and small DOF. As the large volume scanned is on the expense of magnification, such devices suffer from low resolution, which makes taxonomic identification of small species like copepods difficult. Alternatively, systems with throughflow chambers allow constraining the volume physically to the DOF and provide easily manageable and reproducible illumination $[14,15]$. However, the behaviour of the organisms and fine-scale distribution patterns are disturbed by the concentration process and fragile species might be injured [16]. (4) Zooplankton comprises a large number of taxa covering a variety of shapes and surfaces. Additionally, many forms are transparent. As incident light can be transmitted, reflected, scattered or absorbed by the various tissues of an organism, depending on wavelength and the angle between camera, object and illumination source $[17,18]$, imaging the surface and internal structures of small transparent organisms is always a trade-off. Dark field illumination has been proven to deliver robust results for observation of translucent objects [19], but requires high light intensities.

Here, we present images from data subsets obtained during the deployment of light frame on-sight key species investigation (LOKI), a newly developed and versatile in-situ plankton imaging system. It allows imaging of plankton organisms and particles of sizes below $100 \mu \mathrm{m}$ at high resolution, has shutter times $<100 \mu \mathrm{s}$ and a relatively high DOF. We present examples of images of the dominant plankton groups Bacillariophyta, Radiolaria and Acantharia, Euphausiaceae, Ostracoda, Copepoda, Chaetognatha, and Appendicularia, together with some gelatinous forms and larval stages, collected on a cruise to the south east Pacific to discuss details of taxonomic identification.

\section{MATERIALS AND METHODS}

\subsection{Imaging unit}

There are three possible options to deploy the LOKI system (see Figure 1(a)). The different imaging units were developed to cover applications from towed operation (see Figures 1(b) and 1(c)), deployment on moorings (see Figures 1(d) and 1(e)) and towed operation with concentrating plankton net(see Figures $1(\mathrm{f})$ and $1(\mathrm{~g})$ ). Details on the functional principle are presented in [20] and are shortly described here for completeness. The system is based on an illumination technique that either projects a light frame of high luminous flux into the water or constrains the volume physically with transparent boundaries. Particles within this area are illuminated. Only directly illuminated objects are visible for the camera, while those outside the focus range are nearly invisible.

The camera aims with an angle of $90^{\circ}$ at the light frame or the physically constrained and illuminated observation volume (see Figure 1). With a frequency of $15 \mathrm{fps}$, a digital camera with 1.4 million pixels (Prosilica GC1380, equipped with a Schneider-Kreuznach objective and extender rings) takes images of objects within the light frame.

Shutter time is adjustable and generally operated with approximately $45 \mu \mathrm{s}$. The imaging unit uses high power lightemitting diodes (LEDs) as light sources. LEDs are operated with an approximately tenfold higher forward current than specified. Flash mode ensures that the integral of energy over time is similar to continuous mode and prevents the LEDs from overheating.

Quantification of the volume sampled per frame requires knowledge of width, height and depth of the captured volume. While the first two are physically defined by the size of the photosensitive sensor, the principal axis is infinite and needs to be constrained to the DOF. As DOF is narrow, illumination is only necessary within this range. As dimensioning and adjustment must be precise, camera and flash unit are assembled in a way that they are prevented from mechanical displacements. To allow short shutter times, the development of illumination devices with a high light flux and precise targeting (see Figure 1(b)) is a pivotal precondition for in-situ imaging of small planktonic specimens.

Under physically constraint conditions, objects cannot appear in a certain distance before and behind the observation volume's depth. This is achieved by the previously mentioned exclusive illumination in the DOF (see Figure 1(b)) range or by transparent materials (see Figures $1(\mathrm{~d})-1(\mathrm{f})$ ). As a result, images are clearer and background noise is reduced. Between two frames water and entrained, objects are replaced by relative water movement caused by towed operation, tidal currents or mechanically induced flow (e.g. pumps).

\subsection{Recording unit}

Each frame taken by the imaging unit is processed in real time in the underwater unit. Within each frame, areas of interest (AOI) are identified by a threshold and size filter. With a proportional add-on to width and height of the bounding-box of the object's convex hull an AOI is cut off, assigned with a unique time-stamp and stored on hard disc. Only segments of a frame containing an AOI are stored to reduce storage space. Information about the environmental parameters from various sensors (depth, WGS-84, UTC, salinity, temperature, oxygen concentration, etc.) are logged once a second and can be assigned to the AOI by the time stamp. 

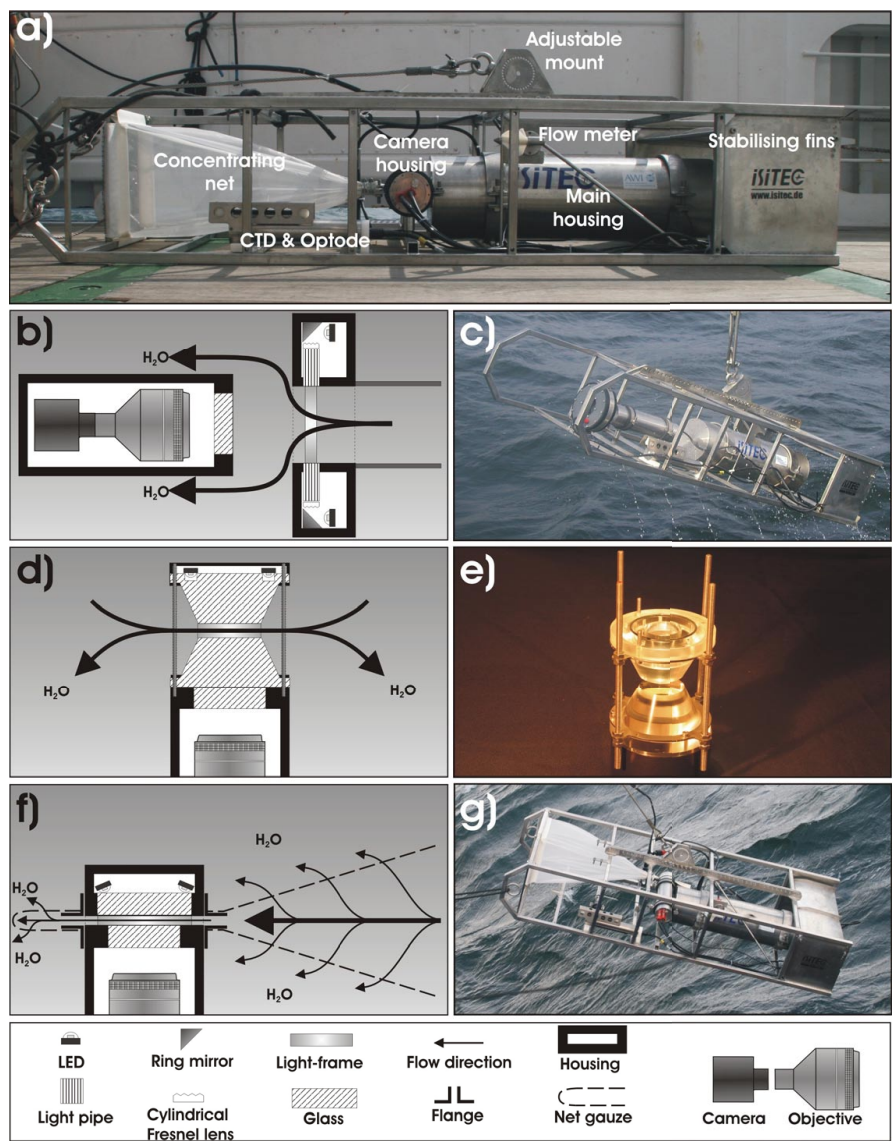

FIG. 1 The LOKI device. (a) Overview of the main parts. (b), (c) Light ring set-up, schematic view of a free through-flow approach and image of the gear. In the ring centre a disc of collimated light illuminates particles from all sides simultaneously and avoids casting shadows. It operates with 55 high power LEDs, collimated by a circular cylindrical Fresnel lens [1]. (d), (e) Schematic overview of the set-up for moored applications and image of the unit during maintenance. (f), (g) Schematic overview of the imaging unit with a flow-cell set-up and image of gear. This application includes an additional net for concentrating and a cod end for sampling.

\subsection{Study area and sampling}

Data presented here were collected with the LOKI system off the Peruvian coast during Cruise M77/4 of R/V "Meteor" from January 30 to February 12, 2009. Vertical hauls were taken from $500 \mathrm{~m}$ (maximum deployment depth) or close to bottom to surface with the net-equipped version of LOKI (200 $\mu \mathrm{m}$ mesh size, mouth opening $0.09 \mathrm{~m}^{2}$, see Figures $1(\mathrm{f})$ and $1(\mathrm{~g}))$ at a heaving speed of $0.3 \mathrm{~ms}^{-1}$. The cross section of the flow-through cell was $15 \mathrm{~mm} \times 4 \mathrm{~mm}$. The dimension of the imaged object plane, perpendicular to the cross section, was $18 \mathrm{~mm} \times 13 \mathrm{~mm}$, recorded by the $2 / 3^{\prime \prime}$ Sony ICX285 chip of the Prosilica camera (1 pix equals $13.4 \mu \mathrm{m}$ ). The system was equipped with an additional net, collecting particles after passing the flow-through chamber. On board preservation of collected specimens in formalin allowed for later detailed taxonomic analysis.

\subsection{Data analysis}

Data were downloaded from the underwater unit after each haul and stored in an SQL based database back end. Postprocessing of sampling data was performed in a browser frontend software (LOKI-browser), that is connecting to the

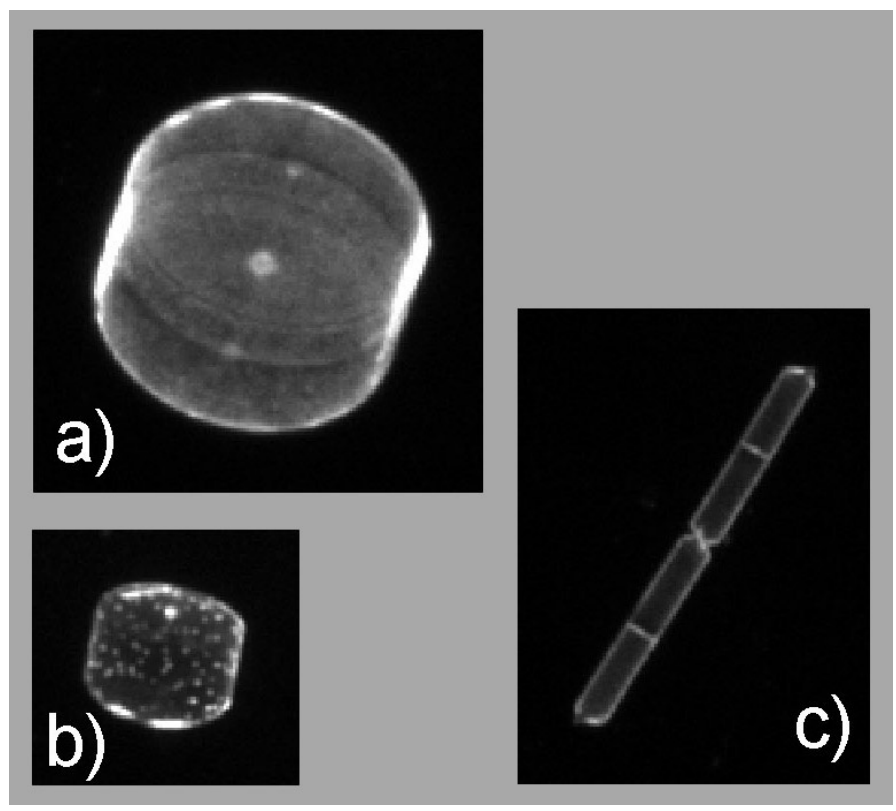

FIG. 2 (a)-(c) Bacillariophyta.

database, visualises recorded images and links data with sensor readings. In the LOKI-browser images were manually assigned to predefined classes of a built-in XML classification tree.

\section{RESULTS}

Images presented here are raw images captured by the LOKI system and were not modified, enhanced, sharpened, cropped or manipulated in any way. Where necessary they were rotated to improve arrangement on the plates (see Figures 2-10). The width (edge length) of each image in the figures is given in Table 1, together with information on position, date, time and water depth of collection. Approximately $40 \%-45 \%$ of the images can be assigned to at least genus or family level, further $40 \%-45 \%$ to higher taxa. About $5 \%-15 \%$ of the images showed detritus, fibres, minerals and indeterminable particles.

\subsection{Bacillariophyta}

Siliceous housings of Bacillariophyta (diatoms) are always imaged as bright structures (see Figures 2(a)-2(c)). Due to their relatively small size and compact structure without appendages they are always correctly extracted by the segmentation algorithm.

\subsection{Radiolaria and Acantharia}

The exoskeleton of Radiolaria and Acantharia always appeared as a bright structure with high contrast (see Figures 3(a)-3(f)). Discrimination of taxa is difficult in these heterogeneous groups. However, Figures 3(a), 3(b) and 3(f) show most probably Radiolarians, while Figures 3(c), 3(d) and 3(e) are obviously Acantharians. 


\begin{tabular}{|c|c|c|c|c|c|}
\hline Image & $\begin{array}{c}\text { GPS-Position } \\
\text { [WGS-84, decimal] }\end{array}$ & $\begin{array}{c}\text { Date } \\
\text { [dd-mm-yyy] }\end{array}$ & $\begin{array}{l}\text { Time } \\
\text { [UTC] }\end{array}$ & $\begin{array}{l}\text { Depth } \\
\text { [dbar] }\end{array}$ & $\begin{array}{l}\text { Image width } \\
\text { [mm] }\end{array}$ \\
\hline 2(a) & $-13.9995 /-084.7508$ & 31.01 .2009 & 07:13:07 & 424.45 & 1.98 \\
\hline 2(b) & $-13.9994 /-084.7509$ & 31.01 .2009 & 07:24:24 & 302.55 & 1.18 \\
\hline 2(c) & $-13.9995 /-084.7507$ & 31.01 .2009 & 07:37:20 & 98.17 & 1.55 \\
\hline $3(\mathrm{a})$ & $-00.0003 /-085.8335$ & 12.02 .2009 & 20:05:30 & 382.67 & 2.94 \\
\hline $3(\mathrm{~b})$ & $-00.0003 /-085.8335$ & 12.02 .2009 & $20: 05: 32$ & 382.06 & 5.25 \\
\hline 3(c) & $-03.5832 /-085.8333$ & 04.02 .2009 & 15:00:46 & 11.49 & 1.66 \\
\hline $3(d)$ & $-14.0000 /-082.5001$ & 30.01 .2009 & $16: 52: 19$ & 293.83 & 0.96 \\
\hline $3(\mathrm{e})$ & $-03.5832 /-083.0001$ & 05.02 .2009 & $14: 27: 34$ & 329.99 & 2.14 \\
\hline $3(\mathrm{f})$ & $-13.9994 /-084.7509$ & 31.01 .2009 & 07:10:37 & 462.81 & 3.16 \\
\hline $4(\mathrm{a})$ & $-13.9999 /-082.5001$ & 30.01 .2009 & $16: 47: 39$ & 362.29 & 8.41 \\
\hline $4(\mathrm{~b})$ & $-13.9995 /-084.7509$ & 31.01 .2009 & 07:42:44 & 7.83 & 4.23 \\
\hline $4(\mathrm{c})$ & $-14.0000 /-082.5001$ & 30.01 .2009 & $17: 13: 21$ & 0.72 & 3.27 \\
\hline $5(\mathrm{a})$ & $-13.9994 /-084.7509$ & 31.01 .2009 & 07:20:48 & 296.42 & 3.00 \\
\hline $5(\mathrm{~b})$ & $-06.0000 /-082.0000$ & 08.02 .2009 & 04:28:11 & 141.15 & 2.03 \\
\hline 5(c) & $-13.9994 /-084.7509$ & 31.01 .2009 & 07:21:08 & 293.33 & 1.50 \\
\hline $5(d)$ & $-03.5923 /-080.9482$ & 06.02 .2009 & 20:51:09 & 157.41 & 2.73 \\
\hline $6(\mathrm{a})$ & $-03.5832 /-085.8334$ & 04.02 .2009 & 14:55:41 & 100.95 & 5.51 \\
\hline 6(b) & $-03.5923 /-080.9482$ & 06.02 .2009 & 20:48:35 & 197.34 & 3.59 \\
\hline 6(c) & $-03.5923 /-080.9482$ & 06.02 .2009 & $20: 48: 43$ & 195.15 & 4.02 \\
\hline 6(d) & $-13.9999 /-085.8334$ & 31.01 .2009 & 19:06:00 & 5.29 & 1.61 \\
\hline $6(\mathrm{e})$ & $-14.0000 /-082.5001$ & 30.01 .2009 & 17:13:12 & 0.73 & 1.66 \\
\hline 6(f) & $-13.9995 /-084.7509$ & 31.01 .2009 & 07:42:18 & 15.06 & 2.03 \\
\hline $6(\mathrm{~g})$ & $-13.9998 /-085.8335$ & 31.01 .2009 & 19:04:54 & 17.80 & 0.96 \\
\hline $6(\mathrm{~h})$ & $-03.5832 /-085.8333$ & 04.02.2009 & 15:01:03 & 6.64 & 2.30 \\
\hline $6(\mathrm{i})$ & $-03.5832 /-083.0000$ & 05.02.2009 & 14:49:02 & 13.89 & 1.34 \\
\hline $6(\mathrm{j})$ & $-05.9999 /-081.2575$ & 30.01 .2009 & 16:52:44 & 148.81 & 3.96 \\
\hline $6(\mathrm{k})$ & $-03.5832 /-083.0001$ & 05.02.2009 & 14:39:51 & 147.07 & 3.05 \\
\hline $6(1)$ & $-13.9995 /-084.7509$ & 31.01 .2009 & $07: 40: 25$ & 46.75 & 2.25 \\
\hline $6(\mathrm{~m})$ & $-13.9995 /-084.7508$ & 08.02.2009 & 20:16:19 & 5.23 & 1.87 \\
\hline $6(\mathrm{n})$ & $-06.0000 /-082.0001$ & 08.02.2009 & $04: 36: 45$ & 9.63 & 2.78 \\
\hline 7(a) & $-06.0000 /-083.7502$ & 08.02 .2009 & $20: 16: 32$ & 4.98 & 13.06 \\
\hline 7(b) & $-12.9999 /-085.8335$ & 01.02 .2009 & 07:39:11 & 25.54 & 5.51 \\
\hline 7(c) & $-03.5832 /-083.0000$ & 05.02 .2009 & $14: 36: 56$ & 198.12 & 1.50 \\
\hline $7(d)$ & $-03.5834 /-082.0163$ & 06.02 .2009 & $04: 48: 42$ & 214.743 & 2.09 \\
\hline 7(e) & $-03.5832 /-083.0001$ & 05.02 .2009 & $14: 19: 13$ & 462.75 & 7.98 \\
\hline $8(\mathrm{a})$ & $-13.9995 /-084.7509$ & 31.01 .2009 & 07:41:43 & 24.74 & 6.10 \\
\hline $8(\mathrm{~b})$ & $-14.0000 /-082.5001$ & 30.01 .2009 & $17: 12: 28$ & 10.28 & 1.55 \\
\hline $8(\mathrm{c})$ & $-06.0000 /-082.0001$ & 08.02 .2009 & 04:34:40 & 42.40 & 5.03 \\
\hline $8(\mathrm{~d})$ & $-06.0000 /-082.0001$ & 08.02 .2009 & 04:34:36 & 43.37 & 2.41 \\
\hline $8(\mathrm{e})$ & $-14.0000 /-082.5001$ & 30.01 .2009 & $17: 12: 24$ & 5.52 & 2.73 \\
\hline 9(a) & $-07.4999 /-085.8334$ & 03.02 .2009 & 09:05:59 & 37.44 & 7.39 \\
\hline 9(b) & $-03.5832 /-085.8333$ & 04.02 .2009 & 15:01:05 & 6.06 & 6.43 \\
\hline 9(c) & $-06.0000 /-082.0002$ & 08.02 .2009 & $04: 37: 29$ & 2.21 & 4.60 \\
\hline 9(d) & $-13.9999 /-085.8334$ & 31.01 .2009 & 19:01:50 & 67.26 & 4.98 \\
\hline 9(e) & $-05.9999 /-082.0000$ & 08.02 .2009 & 04:30:45 & 102.95 & 2.84 \\
\hline $9(\mathrm{f})$ & $-05.9998 /-084.2500$ & 09.02 .2009 & $00: 27: 31$ & 31.64 & 3.48 \\
\hline 10 (a) & $-13.9999 /-085.8334$ & 31.01 .2009 & 19:01:48 & 67.78 & 2.36 \\
\hline $10(\mathrm{~b})$ & $-12.9998 /-085.8334$ & 01.02 .2009 & 07:06:37 & 491.47 & 1.12 \\
\hline $10(\mathrm{c})$ & $-12.9998 /-085.8335$ & 01.02 .2009 & 07:21:17 & 278.23 & 1.29 \\
\hline $10(d)$ & $-03.5832 /-085.8333$ & 04.02 .2009 & 15:01:06 & 5.84 & 1.50 \\
\hline $10(\mathrm{e})$ & $-06.0000 /-082.0000$ & 08.02 .2009 & 04:28:51 & 131.41 & 1.93 \\
\hline $10(\mathrm{f})$ & $-03.5923 /-080.9482$ & 06.02 .2009 & $20: 56: 23$ & 74.90 & 8.73 \\
\hline
\end{tabular}




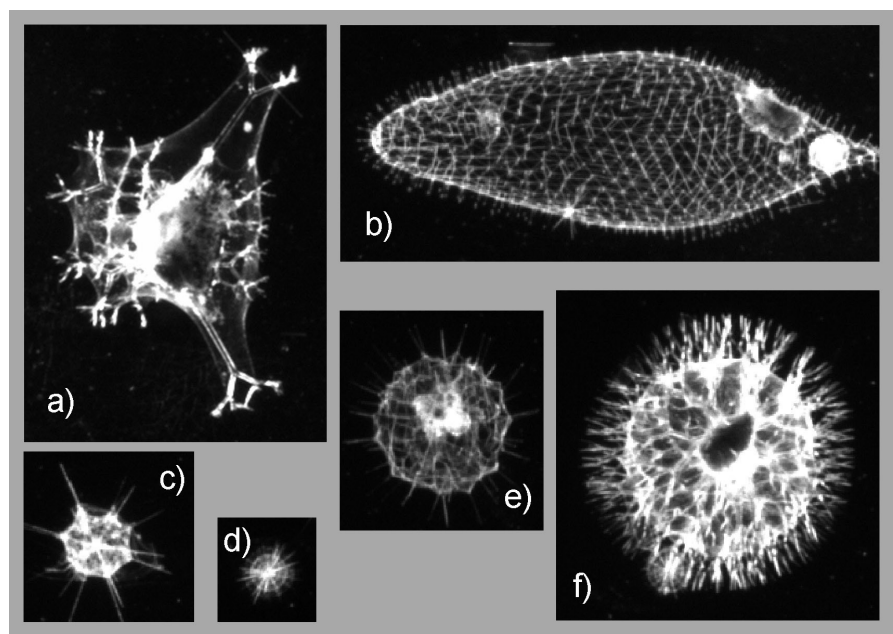

FIC. 3 Radiolaria and Acantharia. (a), (b), and (f) Radiolaria; (c), (d) cf. Acantharia.

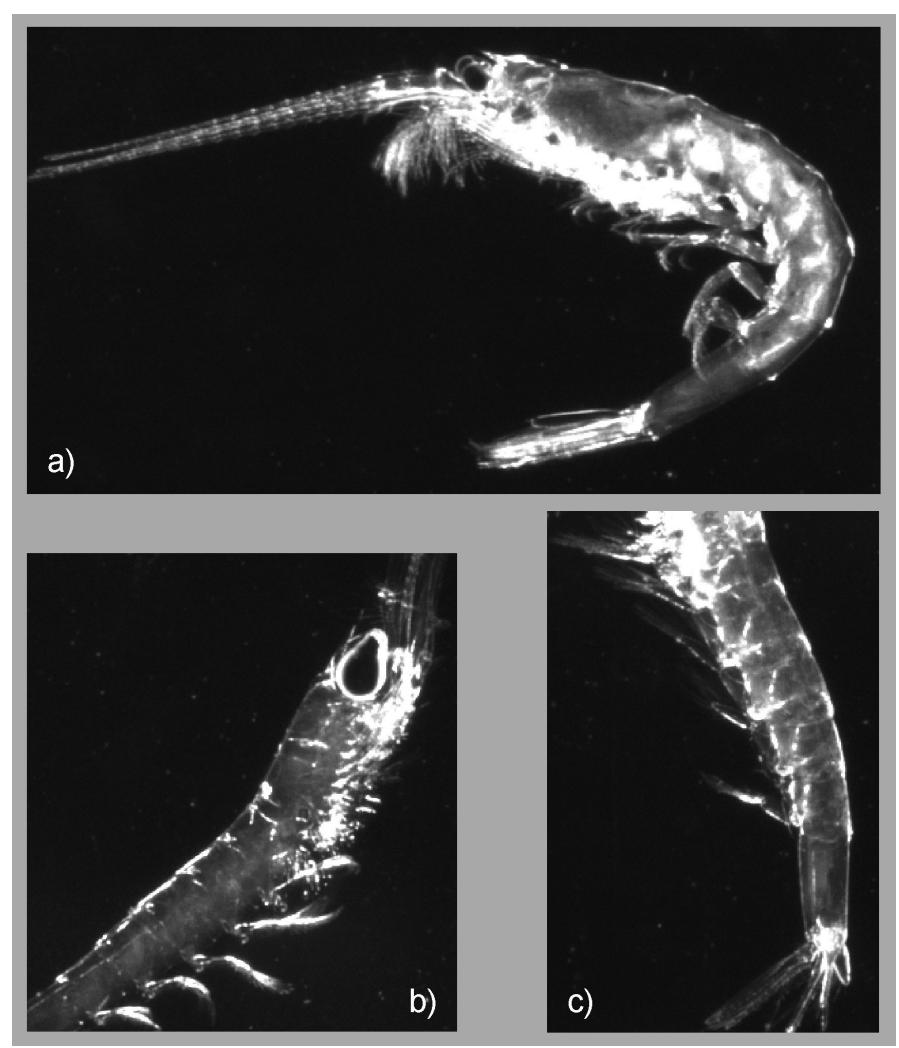

FIG. 4 (a)-(c) Euphausiacea, (b) cf. Stylocheiron sp.

\subsection{Euphausiacea}

Their chitinous exoskeleton allows clear imaging of Euphausiacea. Due to their relatively large size, images appear sharp and show many details like antennae, legs, segmentation, telson and eyes (see Figures 4(a) and 4(b)). Large specimens are often cropped and just partially imaged (see Figure 4(c)). When visible the eye structure (rounded or bilobed, etc.) can be used as a criterion to determine species. Based on the knowledge on the species found in the preserved sample, the specimen in Figure 4(b) is most likely Stylocheiron sp.

\subsection{Ostracoda}

Ostracoda occurred in a high variety of body shape and size. Large specimens often appeared relatively transparent with

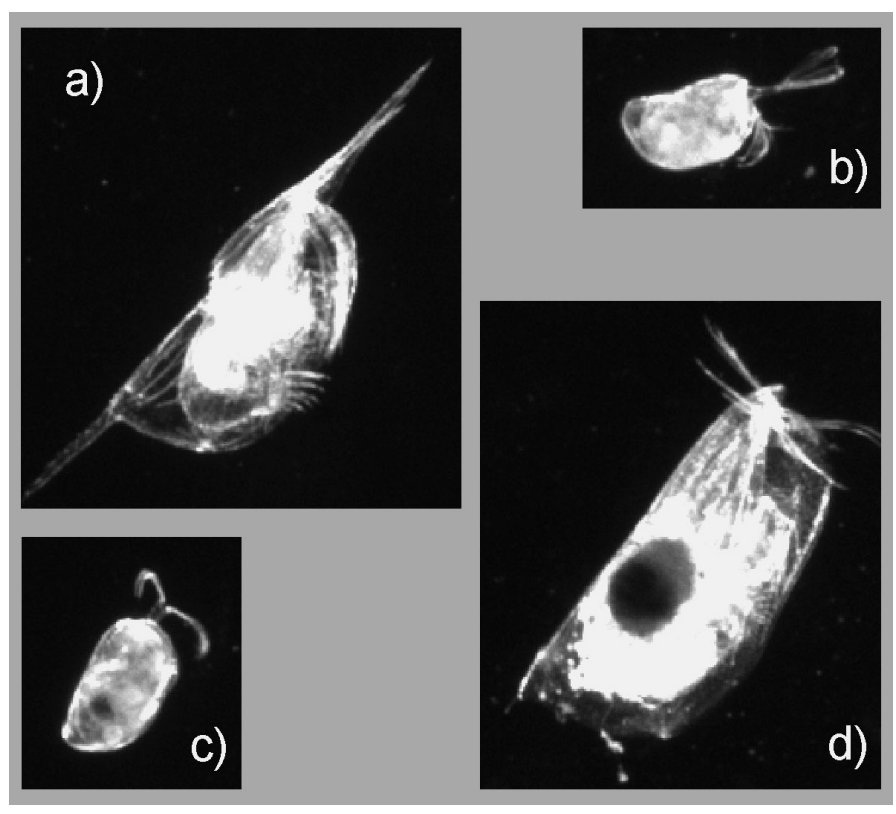

FIG. 5 (a)-(d) 0stracoda. (a) Macroconchoecia caudata.

visible internal structures (see Figures 5(a) and 5(d)). Small specimens were often opaque (see Figures 5(b) and 5(c)). Macroconchoecia caudata is easily to determine due to its long spine extensions of both rostra and an even longer spine of the right carapace valve (see Figure 5(a)). Although many specimens were imaged with high quality, no further classification was possible due to the large number of species in the sample.

\section{$3 \cdot 5$ Copepoda}

The chitinous exoskeleton of these crustaceans results in a well identifiable outline of the body. Fine details (e.g. appendages and furcae) are often not sufficiently clear, probably due to small size or insufficient shutter speed. However, a high percentage of images can be assigned to at least family level as e.g. for the Rhincalanidae (see Figure 6(a)) and Eucalanidae (see Figure 6(j)). Both families include large transparent species, where parts of the antenna and abdomen are often cropped. Several other taxa can be identified to genus level. Copilia sp. (see Figure 6(f)) and Sapphirina sp. (see Figure 6(1)) are easily recognised by their characteristic shape. The same holds for the genus Corycaeus (see Figure 6(i)), where the strongly reflecting ocelli are clearly seen, and Oithona (see Figures 6(d) and 6(n)) with its slender body, long setae and the egg sac. Oncaea spp. apparently has a highly reflective surface and seems over-exposed (see Figures 6(e) and $6(\mathrm{~g})$ ), males and females were often found clinging together in copulation (see Figure 6(g)). Identification of Pleuromamma spp. is only possible with the specimens in a lateral view, showing the characteristic dark brown pigmented spot (see Figure 6(k)). The characteristic appendages at its furca allow clear identification of Calocalanus pavo (see Figure 6(m)). The knowledge on occurring species and their abundance in the sample allows annotating specimens to the genus Calanus (see Figures 6(b) and 6(c)). In Calanus spp. (species in the study area still pending identification), females (see Figure 6(b)) and males (see Figure 6(c)) are clearly separated by the shape of the genital segment and the stronger base of the first antennae 

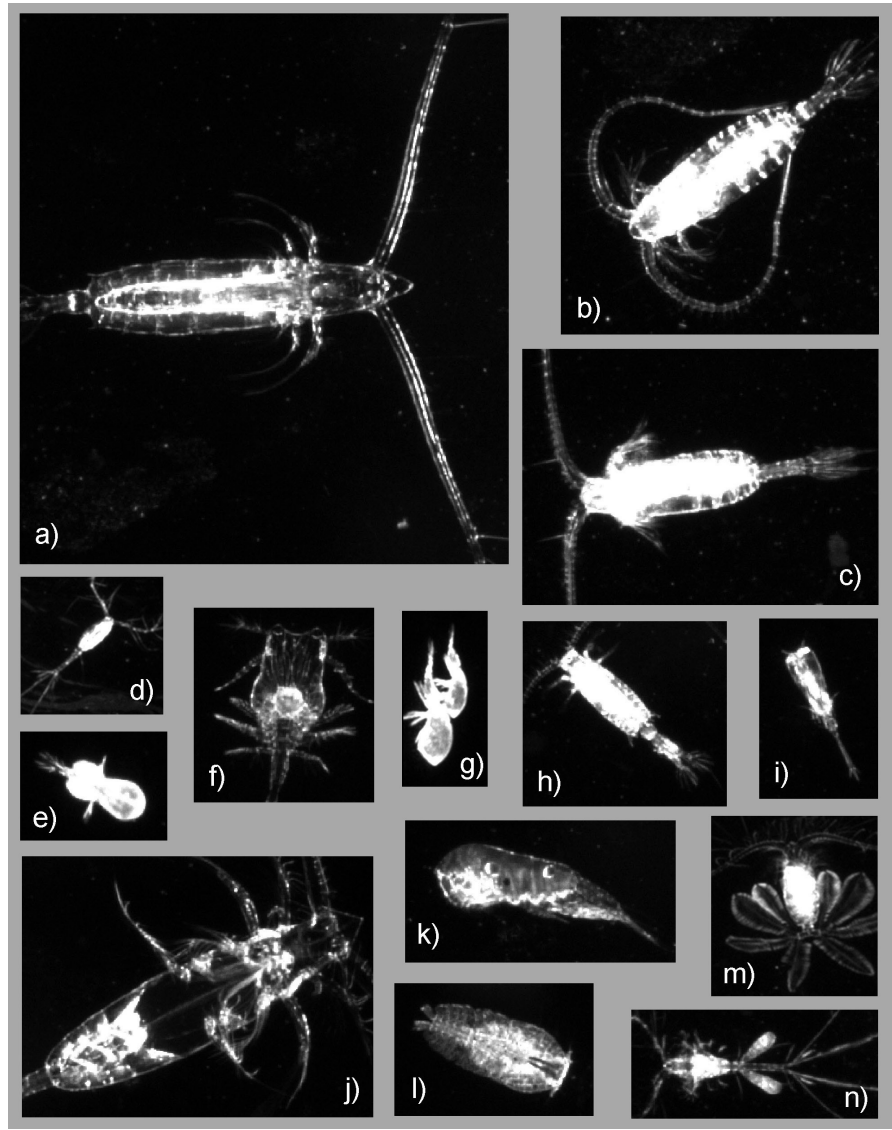

FIG. 6 Copepoda. (a) Rhincalanidae; (b) Calanus sp. female; (c) Calanus sp. male; (d), (n) Oithona spp.; (e), (g) Oncaea spp.; (f) Copilia sp.; (h) Centropages sp.; (i) Corycaeus sp.; (j) Eucalanidae; (k) Pleuromamma sp.; (I) Sapphirina sp.; and (m) Calocalanus pavo.

in the male, and the operculum on the female genital segment.

\subsection{Chaetognatha}

Due to their body length, chaetognaths are often cropped and only partially imaged. The translucent body structure allows the identification of several anatomical features. Male and female gonads of these protandric hermaphrodites can be distinguished (see Figures 7(a) and 7(e)); especially the seminal vesicles are clearly visible (see Figure 7(a)). In Figure 7(d), the body is cropped as apparently the extraction software did not recognise the borders of the animal due to insufficient illumination. Nevertheless, most probably the image is showing a chaetognath specimen in the process of expelling strings of mature eggs. Lateral and tail fins are very transparent and only visible in some cases (see Figure 7(a)). The chitinous grasping spines sometimes appear as bright borders around the head (see Figure 7(c)). Insertion sites of the ciliar sensors on the epidermis appear as small spots (see Figures 7(a) and 7(b)). The bristles are seldom directly visible. In some cases food particles in the gut are visible (see Figure 7(b)). In the samples, several Sagitta species occurred but determination to species level was not possible.

\subsection{Appendicularia}

The fragile Appendicularians are mainly translucent and exhibit few highly refractive parts. Thus, visualisation is the best

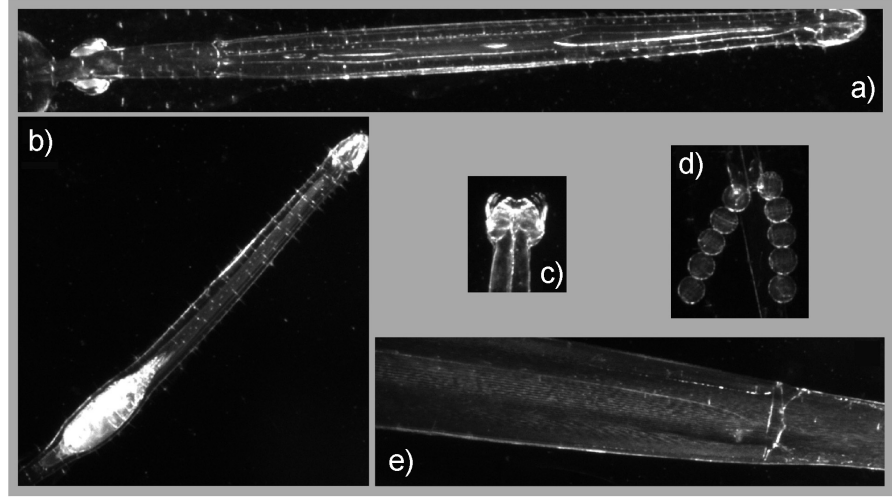

FIG. 7 (a)-(e) Chaetognatha.

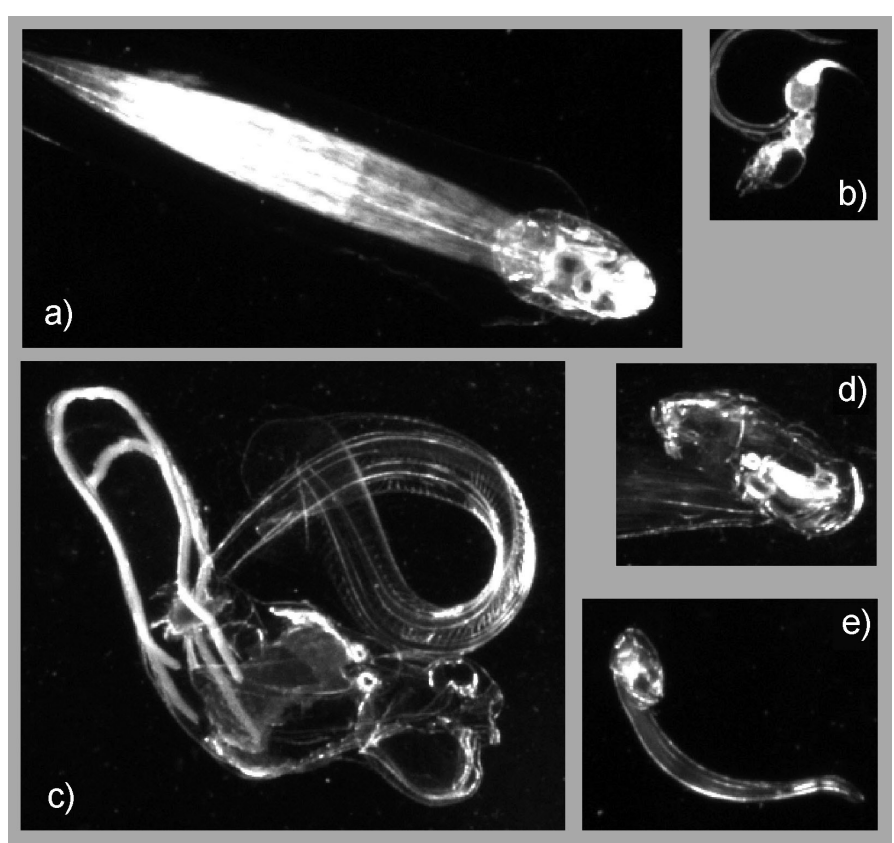

FIG. 8 Appendicularia. (a), (d), (e) Oikopleura spp.; (b), (c) Fritillaria spp.

where several tissues are consecutively arranged along the principal imaging axis. The characteristic shape of the trunk allows discriminating between the genera Oikopleura (see Figures 8(a), 8(d), and 8(e) and Fritillaria (see Figures 8(b) and $8(\mathrm{c})$ ), the only appendicularian genera found in the samples. The notochord, musculature and tail fin can be identified in whole individuals (see Figures 8(a) and 8(c)). The housing and filter apparatus is nearly always missing. In Figure 8(c), bright cramps attached to the trunk might be fragments of a frittilarian filter apparatus.

\subsection{Gelatinous zooplankton}

Gelatinous forms of different taxonomic groups are imaged well. In ctenophores (see Figures 9(a) and 9(c)), the characteristic comb rows, distinguished by the ctenes (fused ciliary plates) aid identification. The organisms are transparent enough to see parts of the gastrovascular system and tentacle sheaths. Due to their size, some specimens are cropped and only partially imaged (see Figure 9(c)). Small colonies of Siphonophora are often fully imaged (see Figure 9(b)). This group can also be identified on partial images. Doliolid thaliaceans (see Figure 9(f)) can appear as nearly 3-dimensional 


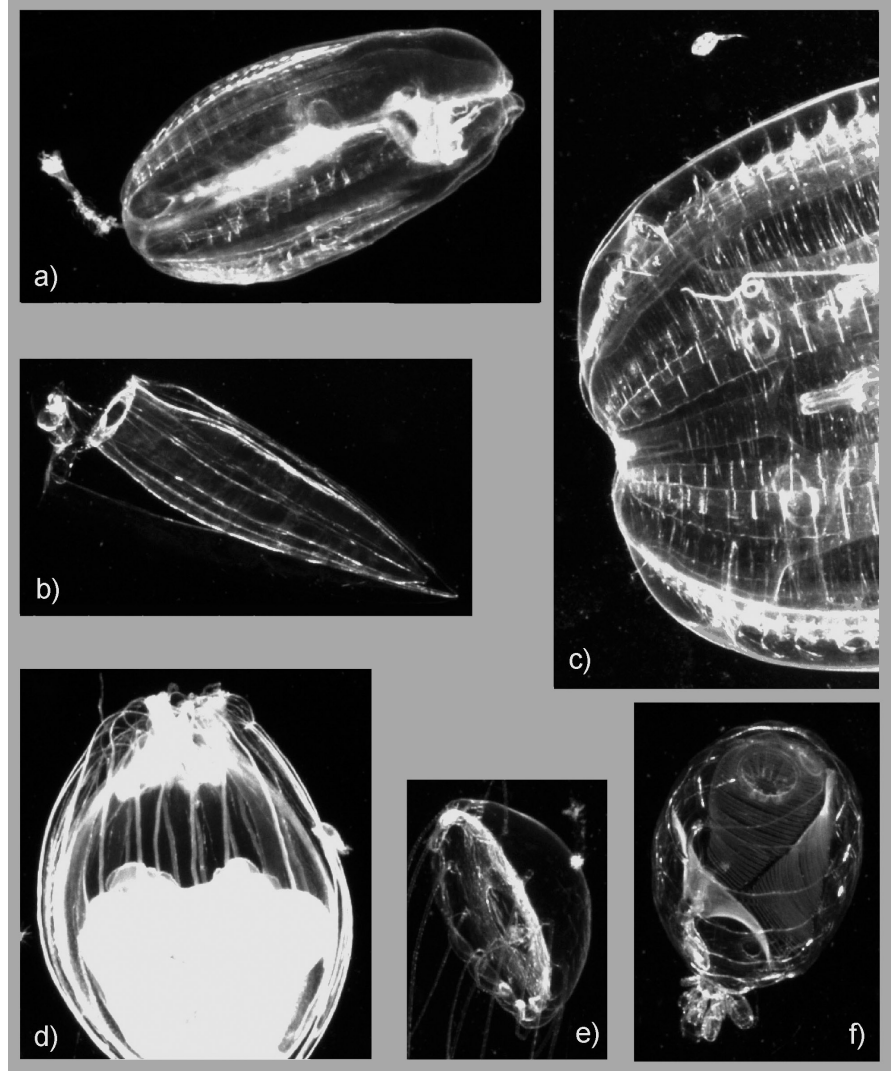

FIG. 9 Gelatinous zooplankton. (a), (c) Ctenophora; (b) Siphonophora; (d), (e) Hydromedusa; and (f) Thaliacea.

images showing the branchial and atrial siphons as well as anatomical structures including the branchial basket. Hydromedusae occurred in variable sizes. The large specimens are often cropped and appear overexposed (see Figure 9(d)). The small specimen in Figure 9(e) is almost transparent, but umbrella, manubrium and tentacles are visible.

\subsection{Larvae and eggs}

Larval stages are often more than one order of magnitude smaller than their adult stages. Within the nauplii stages of crustaceans the two pairs of antennae ( 1 and 2 ) and one pair of mandibles can often be distinguished (see Figures 10(b)10(d)). In other invertebrate larvae (see Figure 10(e), probably holothurian larva), the ciliar bands around the body can be clearly identified. In translucent fish eggs head and segmentations of the developing larvae can often be seen (see Figure 10(a)). Also hatched fish larvae can be found in the samples (see Figure 10(f)) showing anatomical features like vertebrae, entrails and fins.

\section{DISCUSSION}

\section{1 In-situ plankton imaging}

The LOKI system has been designed for in-situ imaging of zooplankton and particles in the water column. The system allows small scale investigations and a spatial resolution unapproachable with plankton nets. Images are digitally linked with concurrently measured environmental parameters (see Table 1) from a variety of sensors and can easily be queried
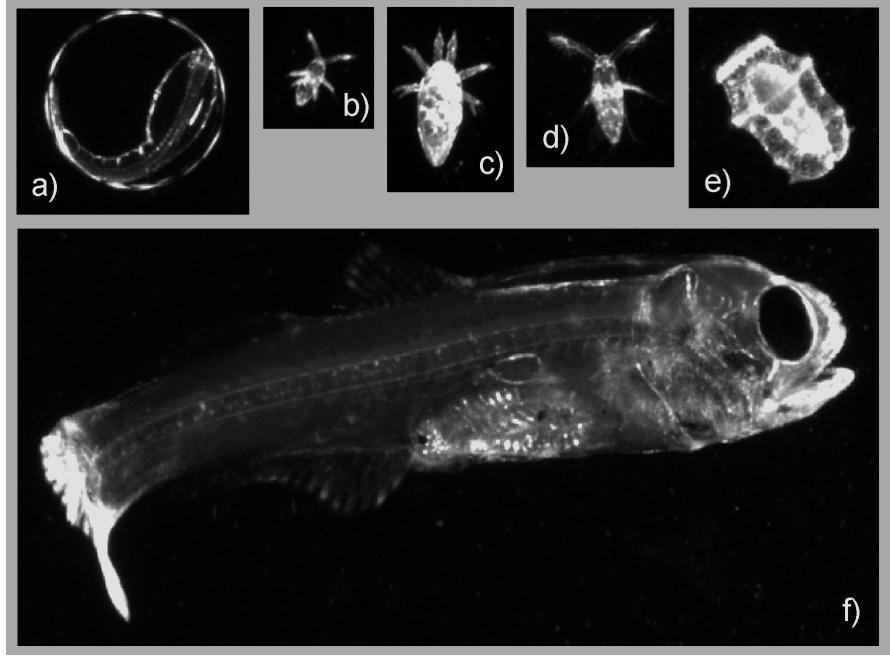

FIG. 10 Larvae and eggs. (a) Fish egg; (b)-(d) Nauplii; (e) Invertebrate larva; (f) Fish larvae.

and investigated for characteristic species compositions in relation to the ambient hydrography. Creation of a constrained light-frame within the DOF reduces the number of out-offocus images despite high magnification. Circular arrangement of LEDs around the sampling volume avoids that larger objects cast shadows and results in a homogeneous illumination level even with large organisms (see Figures 6(a)-6(c), 7(c), 8(a), 9(a), 9(c), 9(f) and 10(f)). Fine bristles and setae with diameters $<50 \mu \mathrm{m}$ can be identified in all size classes. With decreasing object size details are not imaged by individual pixels, but rather by grey mean values due to aliasing effects.

The continuous imaging mode exposes without respect to object position within the sampling volume and results in series of images showing cropped specimens. This problem is amplified with increasing object size (see Figure 4(c) and 9(c)). When appendages are less bright, the real-time segmentation algorithm in the underwater unit often crops these parts. Increasing the bounding box is just partially helpful as other particles in the vicinity may be combined. Compact and small structures always foster real-time segmentation and result in mainly uncropped images.

\subsection{Taxonomy}

In most cases exoskeletons are visible as bright structures in the images, defining the organisms. Especially textured surfaces and interior muscular insertion points show reflexions within certain parts of an organism (see Figures 4(a)-4(c), 7(c) and $9(\mathrm{~d})$ ). With decreasing body size this effect expands relatively and can be observed in most parts of the organism, reducing perceptibility of interior details. Radiolaria and Acantharia however, are an exception. While their skeletons are always well imaged, their interior structures are seldom visible. Species with dense pigmentation, like Oncaea spp. [21], are mainly imaged as opaque silhouettes (see Figures 6(e) and $6(\mathrm{~g}))$. This in turn seems to be a characteristic property of a genus and can be used for discrimination.

In organisms without an exoskeleton outlines are often weakly imaged (see Figures 7(a), 8(b), 8(c) and 9(e)). This 
effect decreases with increasing size (see Figures 9(a), 9(c) and 9(d)), higher pigmentation or more complex tissues stacked in the direction of the optical axis. Transparent organisms often allow good insight into anatomic details like gonad condition, gut content, or lipid droplets (see Figures 6(a), 6(f), 7(b), 7(e), 8(c), 9(a)-9(f), and 10(a)). Most images display enough sufficient details to annotate organisms to family or genus level. Incorporating knowledge on species composition from the preserved samples helps greatly assigning images to species level, as the number of potential species is often drastically reduced.

\subsection{Comparison between systems}

Numerous systems for in-situ plankton observation have been developed in the past using imaging approaches such as photography, video techniques, line scan cameras, and holography (see review in [4]), but only few systems are commercially available. Among them, digital video cameras are used by the Video Plankton Recorder (VPR, [22]), the Underwater Video Profiler (UVP, [23]), and the LOKI system presented here. The underlying concepts differ with respect to sampling mode and imaged volume and hence image quality and resolution of taxonomic details. Furthermore, choice of sampling volume reflects always a compromise between high resolution image quality and representative sampling of the community, as the probability to detect a species depends on its abundance $[22,24]$.

Different light heads of LOKI were designed to adapt the sampling strategy according to the scientific goal. The system used in this study with a concentrating net follows traditional plankton net sampling; however with much higher spatial resolution. A similar set-up using silhouette photography in the cod end of a net has previously been used by [25]. In such systems, depending on net diameter and mesh size, the sample may represent also less abundant species within a certain size fraction of the community.

The VPR [22] uses forward scattered light and images volumes in the range of $<1 \mathrm{ml}$ up to a $150 \mathrm{ml}$, that are defined by the light sheet produced by the illumination system and the DOF of the optical system used. Several cameras can be used to image different volume sizes simultaneously in order to provide information on several size classes of plankton. The system permits sampling of fragile forms such as jellyfish, algae, dinoflagellates and marine snow without damage and thus to study natural morphology and behaviour [26].

The UVP was principally dedicated to the undisturbed quantitative study of marine aggregates and large zooplankton, with the resolution and sampling volume depending on the camera systems used (e.g. see [27]). A double camera system increases the size spectrum.

Another very promising approach of in-situ plankton imaging makes use of holographic techniques [28]-[31]. The great advantage of these systems is the large amount of water scanned per hologram (up to several $100 \mathrm{ml}$ ) and the option to simultaneously analyse spatial interrelationships between specimens. Holographic techniques are also capable to resolve fine structures, like bristles, but post-processing is time consuming [30]. Digital holograms are often lower in resolution, with the chip size of the recording camera being the limiting factor [30]. Anyhow, sophisticated algorithms allow reconstruction of digital holographic data in nearly real-time [32]. A disadvantage of this technique is the reduced capacity to display internal structures and the high background noise due to interferences around the object. This complicates successive approaches of automated image segmentation and classification, which are necessary for operative applications.

\subsection{Conclusion and outlook}

The image quality obtained with the LOKI system is sufficient to distinguish dominant groups of marine zooplankton organisms at least to family level. With the illumination and optical set-up of the LOKI system it is possible to capture high quality in-situ images of marine plankton with little background noise and high contrast. The size range covered by the system allows investigating a wide range of species being crucial for the food web and ecosystem functioning. Adaptation of the sample volume would allow focusing on other size groups. As photonic technologies are advancing so are optical tools for operational oceanography, among them imaging flow cytometers and multi-wavelength fluorescence probes [33]. These technologies incorporate high power ultraviolet light sources for fluorescence signature detection. Merging these techniques with zooplankton imaging allows gaining more detailed information on inherent and characteristic optical properties of the imaged objects. However, these multidimensional data sets foster the need for algorithms to improve semi-automated and automated image analysis in near real-time.

\section{ACKNOWLEDGEMENTS}

LOKI was developed in cooperation with iSiTEC GmbH Bremerhaven. We thank Heiko Lilienthal, Norbert Rieper, Jan Hoops and Thomas Hanken for their continuous work on the system. Kurt Vogel from medeaAV was a partner in developing the LOKI software. Dr. Eva-Maria Nöthig, Dr. Cornelia Buchholz and Dr. Eduard Bauerfeind from Alfred-WegenerInstitute (Bremerhaven) helped in specimen identification and Renate Kuchta arranged images for publication. Sven Neumann aided the process of script developing for data processing. Dr. Tobias Gerdes gave important hints for the copy editing of this article. And finally we have to thank John Watson and Werner Jüptner for initiating the EOS "Blue Photonics" conference.

This development was funded by the Bremerhavener Gesellschaft für Investitionsförderung und Stadtentwicklung $\mathrm{mbH}$ (BIS 56008/2-Z and BIS 68036/2-Z), co-financed by the European Community. The IMARE $\mathrm{GmbH}$ is subsidised by ERDF (European Regional Development Fund). 


\section{References}

[1] J. Schulz, C. Möllmann, and H.-J. Hirche, "Vertical zonation of the zooplankton community in the central Baltic Sea in relation to hydrographic stratification as revealed by multivariate discriminant function and canonical analysis" J. Marine Syst. 67, 47-58 (2007).

[2] K. G. Foote, "Optical methods" in ICES Zooplankton Methodology Manual, R. P. Harris, P. H. Wiebe, J. Lenz, H. R. Skjoldal, M. Huntley, eds., 259-295 (2000).

[3] J. S. Jaffe, D. E. Moore, J. McLean, and M. P. Strand, “Underwater optical imaging: status and prospects" Oceanography 14, 61-75 (2001).

[4] P. H. Wiebe, and M. C. Benfield, "From the Hensen net toward four-dimensional biological oceanography" Prog. Oceanogr. 56, 7136 (2003).

[5] J. Pollio, R. Meyer, and L. D. Sivak, "Model analysis of underwater photographic and visibility systems from observed data" in Proceedings of the Society Photo-Optical Instrumental Engineering: Ocean Optics VI, S. Q. Duntley, ed., 208, 232-241 (Bellingham, Washington, 1979).

[6] J. R. Strickler, "Observation of swimming performances of planktonic copepods" Limnol. Oceanogr. 22, 165-170 (1977).

[7] G. Schröder, and H. Treiber, Technische Optik. Grundlagen Und Anwendungen (Vogel, Germany, 2002).

[8] A. T. Mustard, M. D. Conquer, and J. T. Allen, “Laboratory evaluation of a high specification digital CMOS camera for imaging zooplankton at high towing speeds" in Southampton Oceanography Centre, Internal Document 89, 17 (2003).

[9] C. S. Davis, S. M. Gallager, M. Marra, and W. K. Stewart, "Rapid visualization of plankton abundance and taxonomic composition using the video plankton recorder" Deep-Sea Res. 43, 1947-1970 (1996).

[10] M. C. Benfield, R. F. Shaw, and C. Schwehm, "Development of a vertically profiling, high-resolution, digital still camera system" in ONR Annual Report Office Navy Research, NR Grant No: Nooo14-981-0563, 6 (2000).

[11] G. Gorsky, M. Picheral, and L. Stemmann, "Use of the underwater video profiler for the study of aggregate dynamics in the North Mediterranean" Estuar. Coast. Shelf S. 50, 121-128 (2000).

[12] W. M. Graham, D. L. Martin, and J. C. Martin, "In situ quantification and analysis of large jellyfish using a novel video profiler" Mar. Ecol.-Prog. Ser. 254, 129-140 (2003).

[13] M. Lunven, P. Gentien, K. Kononen, E. Le Gall, and M. M. Daniélou, "In situ video and diffraction analysis of marine particles" Estuar. Coast. Shelf S. 57, 1127-1137 (2003).

[14] J. Lenz, D. Schnack, D. Petersen, J. Kreikemeier, B. Hermann, S. Mees, and K. Wieland, "The Ichthyoplankton Recorder: a video recording system for in situ studies of small-scale plankton distribution patterns" ICES J. Mar. Sci. 52, 409-417 (1995).

[15] S. Samson, T. Hopkins, A. Remsen, L. Langebrake, T. Sutten, and J. Patten, "A system for high-resolution zooplankton imaging" IEEE J. Ocean Eng. 26, 671-676 (2001).

[16] K. Wieland, B. Hermann, J. Kreikemeier, J. Lenz, S. Mees, and D. Schnack, "Preliminary results of the small scale distribution of herring larvae in the English Channel as obtained by means of a towed video recording system" Deep-Sea Res. 30, 331-342 (1992).

[17] G. Chapman, "Transparency in organisms" Cell. Mol. Life Sci. 32, 123-125 (1976).
[18] S. Johnsen, "Hidden in plain sight: the ecology and physiology of organismal transparency" Biol. Bull. 201, 301-318 (2001).

[19] U. Kils, "On the micro-structure of micro layers. Results of an insitu zooplankton-counter" ICES CM 1989/L 15, 1-4 (1989).

[20] J. Schulz, K. Barz, D. Mengedoht, T. Hanken, H. Lilienthal, N. Rieper, J. Hoops, K. Vogel, and H.-J. Hirche, Lightframe On-sight Key species Investigation (LOKI) - The art of imaging tiny plankton species onthe-fly (IEEE Oceans'09: Balancing technology with future needs, Bremen, 11-14 May, 2009).

[21] T. A. Clarke, "Diets of fourteen species of vertically migrating mesopelagic fishes in Hawaiian waters" Fish B-NOAA 78, 619-640 (1980).

[22] C. S. Davis, S. M. Gallager, M. S. Berman, L. R. Haury, and J. R. Strickler, "The video plankton recorder (VPR)- design and initial results" Ergeb. Limnol. 36, 67-81 (1992).

[23] G. Gorsky, C. Aldorf, M. Kage, M. Picheral, J. Garcia, and J. Favole, "Vertical distribution of suspended aggregates determined by a new underwater video profiler" Ann. I. Oceanogr. Paris 68, 13-23 (1992).

[24] M. C. Benfield, C. S. Davis, P. H. Wiebe, S. M. Gallager, R. G. Lough, and N. J. Copley, "Video plankton recorder estimates of copepod, pteropod and larvacean distributions from a stratified region of Georges Bank" Deep-Sea Res. Pt. II 43, 1925-1945 (1996).

[25] J. E. Olney, and E. D. Houde, "Evaluation of in situ silhouette photography in investigations of estuarine zooplankton and ichthyoplankton" B. Mar. Sci. 52, 845-872 (1993).

[26] C. J. Ashjian, C. S. Davis, S. M. Gallager, and P. Alatalo, "Characterization of the zooplankton community, size composition, and distribution in relation to hydrography in the Japan/East Sea" DeepSea Res. Pt. II 52, 363-392 (2005).

[27] L. Stemmann, M. Youngbluth, K. Robert, A. Hosia, M. Picheral, H. Paterson, F. Ibanez, L. Guidi, F. Lombard, and G. Gorsky, "Clobal zoogeography of fragile macrozooplankton in the upper 100-1000 $\mathrm{m}$ inferred from the underwater video profiler" ICES J. Mar. Sci. 65, 433-442 (2008).

[28] K. L. Carder, R. G. Steward, and P. R. Betzer, "In situ holographic measurements of the sizes and settling rates of oceanic particulates" J. Geophys. Res. 87, 5681-5685 (1982).

[29] J. Watson, S. Alexander, G. Craig, D. C. Hendry, P. R. Hobson, R. S. Lampitt, J. M. Marteau, H. Nareid, M. A. Player, K. Saw, and K. Tipping, "Simultaneous in-line and off-axis subsea holographic recording of plankton and other marine particles" Meas. Sci. Technol. 12, 9-15 (2001).

[30] E. Malkiel, J. N. Abras, E. A. Widder, and J. Katz, "On the spatial distribution and nearest neighbor distance between particles in the water column determined from in situ holographic measurements" J. Plankton Res. 28, 149-170 (2006).

[31] H. Sun, P. W. Benzie, N. Burns, D. C. Hendry, M. A. Player, and J. Watson, "Underwater digital holography for studies of marine plankton" Philos. T. Roy. Soc. A 366, 1789-1806 (2008).

[32] E. Malkiel, J. Sheng, J. Katz, and J. R. Strickler, "The threedimensional flow field generated by a feeding calanoid copepoed measured using digital holography" J. Exp. Biol. 206, 3657-3666 (2003).

[33] C. Moore, A. Barnand, P. Fietzek, M. Lewis, H. Sosik, S. White, and 0 . Zielinski, "Optical tools for ocean monitoring and research" Ocean Sci. 5, 661-684 (2009). 